\title{
COOLING MICROELECTRONIC DEVICES USING OPTIMAL MICROCHANNEL HEAT SINKS
}

\author{
Jorge Mario Cruz DuARtE ${ }^{1}$ \\ IVÁN MAURICIO AMAYA CONTRERAS ${ }^{2}$ \\ CARLOS RODRIGO CORREA CELY ${ }^{3}$
}

\section{ABSTRACT}

This article deals with the design of optimum microchannel heat sinks through Unified Particle Swarm Optimisation (UPSO) and Harmony Search (HS). These heat sinks are used for the thermal management of electronic devices, and we analyse the performance of UPSO and HS in their design, both, systematically and thoroughly. The objective function was created using the entropy generation minimisation criterion. In this study, we fixed the geometry of the microchannel, the amount of heat to be removed, and the properties of the cooling fluid. Moreover, we calculated the entropy generation rate, the volume flow rate of air, the channel width, the channel height, and the Knudsen number. The results of several simulation optimizations indicate that both global optimisation strategies yielded similar results, about 0.032 $\mathrm{W} / \mathrm{K}$, and that HS required five times more iterations than UPSO, but only about a nineteenth of its computation time. In addition, HS revealed a greater chance (about three times) of finding a better solution than UPSO, but with a higher dispersion rate (about five times). Nonetheless, both algorithms successfully optimised the design for different scenarios, even when varying the material of the heat sink, and for different heat transfer rates.

KEYWORDS: Entropy Generation Minimisation; Global Optimization Algorithm; Microchannel Heat Sink; Optimal Design

\section{DISEÑO ÓPTIMO DE MICROCANALES. UNA COMPARACIÓN DE DOS ALGORITMOS DE OPTIMIZACIÓN GLOBAL}

\section{RESUMEN}

Este artículo trata sobre el diseño óptimo de disipadores de calor de tipo microcanal utilizando los métodos Unified Particle Swarm Optimisation (UPSO) y Harmony Search (HS). Estos disipadores se utilizan en el enfriamiento de componentes microelectrónicos. Por ello analizamos el desempeño de UPSO y HS en su diseño, de forma sistemática y completa. La función

1 Ingeniero electrónico, M.Sc., Estudiante de doctorado, Universidad de Guanajuato, División de Ingenierías, Campus Irapuato-Salamanca, Salamanca, México.

2 Ingeniero mecatrónico, Universidad Autónoma de Bucaramanga (UAB), Colombia. PhD. en Ingeniería (Ingeniería Eléctrica, Electrónica y Gestión \& Desarrollo) Universidad Industrial de Santander (UIS). Profesor cátedra, E3T, Universidad Industrial de Santander, Bucaramanga, Colombia.

3 Ingeniero químico Universidad Nacional de Colombia. Magíster en Ingeniería Química, Lehigh University, Estados Unidos. PhD.en Ingeniería Química Lehigh University USA. Trabajo Postdoctoral, University of Stuttgart, Alemania. Profesor titular, E3T, Universidad Industrial de Santander, Bucaramanga, Colombia.

Autor de correspondencia: Cruz-Duarte, J.M. (Jorge Mario). Universidad de Guanajuato, División de Ingenierías, Campus Irapuato-Salamanca, Carretera Salamanca-Valle de Santiago km $3.5+1.8$ km, Comunidad de Palo Blanco, C.P. 36885, Salamanca, Guanajuato, México / Tel.: (521) 464647 9940, Ext. 2400 / Correo electrónico: jorge.cruz@ugto.mx
Historia del artículo:

Artículo recibido: 22-IV-2015 / Aprobado: 26-VIII-2015

Disponible online: 30 de octubre de 2015

Discusión abierta hasta noviembre de 2016 
objetivo se obtuvo con el criterio de la mínima generación de entropía. En este estudio, se definió la geometría del microcanal, la cantidad de calor a ser retirado y las propiedades del fluido de trabajo. Además, se calculó la tasa de generación de entropía, el flujo volumétrico de aire, el ancho y la altura del canal y el número de Knudsen. Los resultados de las simulaciones indicaron que ambas estrategias de optimización dieron resultados similares, alrededor de 0,032 W / K, y que HS requiere cinco veces más iteraciones que UPSO, pero sólo alrededor de 1/19 de su tiempo de cálculo. Además, HS reveló una mayor probabilidad de encontrar una mejor solución que UPSO, pero con una mayor dispersión. Sin embargo, ambos algoritmos resolvieron exitosamente el diseño para diferentes escenarios, incluso cuando se varía el material del disipador y la tasa de transferencia de calor.

PALABRAS CLAVE: algoritmos de optimización global; diseño óptimo; disipadores de calor de tipo microcanal; mínima generación de entropía.

\section{DESIGN ÓTIMO DE MICROCANAIS. UMA COMPARAÇÃO DOS DOIS ALGORITMOS DE OPTIMIZAÇÃO GLOBAL}

\section{RESUMO}

Este artigo discute o projeto ideal de dissipadores de calor de microcanais utilizando os métodos Unified Particle Swarm Optimization (UPSO) e Harmonia Search (HS). Estes resfriadores são utilizados em refrigeração com componentes microeletrônicos. Por isso, vamos analisar o desempenho de UPSO e HS na sua concepção, de uma forma sistemática e completa. A função objetivo foi obtida com o critério de geração mínima de entropia. Neste estudo, definiu-se a geometria de microcanais, a quantidade de calor a ser removida e as propriedades do fluido de trabalho. Além disso, se calculo a taxa de geração de entropia, o caudal volumétrico de ar, a largura e a altura do canal e o número de Knudsen. Os resultados da simulação indicaram que ambas das estratégias de otimização deram resultados semelhantes, cerca de $0.032 \mathrm{~W} / \mathrm{K}$, e que HS exige cinco vezes mais iterações UPSO, mas apenas cerca de 1/19 do seu tempo de computação. Também, HS revelou uma maior probabilidade de encontrar uma solução melhor do que UPSO, mas com maior dispersão. No entanto, ambos dos algoritmos resolveram com sucesso o design para diferentes cenários, mesmo quando o material do pia e a taxa de transferência de calor é variada.

PALAVRAS-CHAVE: algoritmos de otimização globais; design ideal; dissipadores de calor de tipo microcanal; geração mínima de entropia.

\section{Nomenclature}

C Adimensional parameter

$C_{p} \quad$ Specific heat at constant pressure $(\mathrm{J} / \mathrm{kg} \cdot \mathrm{K})$

$C_{v} \quad$ Specific heat at constant volume $(\mathrm{J} / \mathrm{kg} \cdot \mathrm{K})$

$D_{h} \quad$ Hydraulic diameter $\equiv 4 H_{c} w_{c} /\left(H_{c}+2 w_{c}\right)(m)$

FW Fretwidth

$F \quad$ Friction factor

$G \quad$ Volume flow rate $\left(\mathrm{m}^{3} / \mathrm{s}\right)$

$\mathcal{G}$ Global velocity component

$H_{c} \quad$ Channel height $(m)$

HMCR Harmony Memory Consideration Rate

HMS Harmony Memory Size

$h_{\text {avg }} \quad$ Average heat transfer coefficient $\left(\mathrm{W} / \mathrm{m}^{2} \cdot K\right)$
Kn Knudsen number

$k \quad$ Thermal conductivity of solid $(\mathrm{W} / \mathrm{m} \cdot \mathrm{K})$

$k_{c e} \quad$ Sum of entrance and exit losses

$k_{f} \quad$ Thermal conductivity of fluid $(\mathrm{W} / \mathrm{m} \cdot \mathrm{K})$

$L \quad$ Length of cannel in flow direction $(m)$

$\mathcal{L} \quad$ Local velocity component

$N \quad$ Total number of microchannels

$N u_{D_{h}}$ Nusselt number base on hydraulic diameter $\equiv$ $D_{h} h_{\text {avg }} / k_{f}$

$n \quad$ Total number of design variables

$P \quad$ Pressure (Pa)

PAR Pitch Adjusting Rate

$P e_{D_{h}} \quad$ Peclet number base on hydraulic diameter $\equiv$ $D_{-} h U_{-}\{a v g\} / \mid a l p h a_{-}\{t h\}$ 


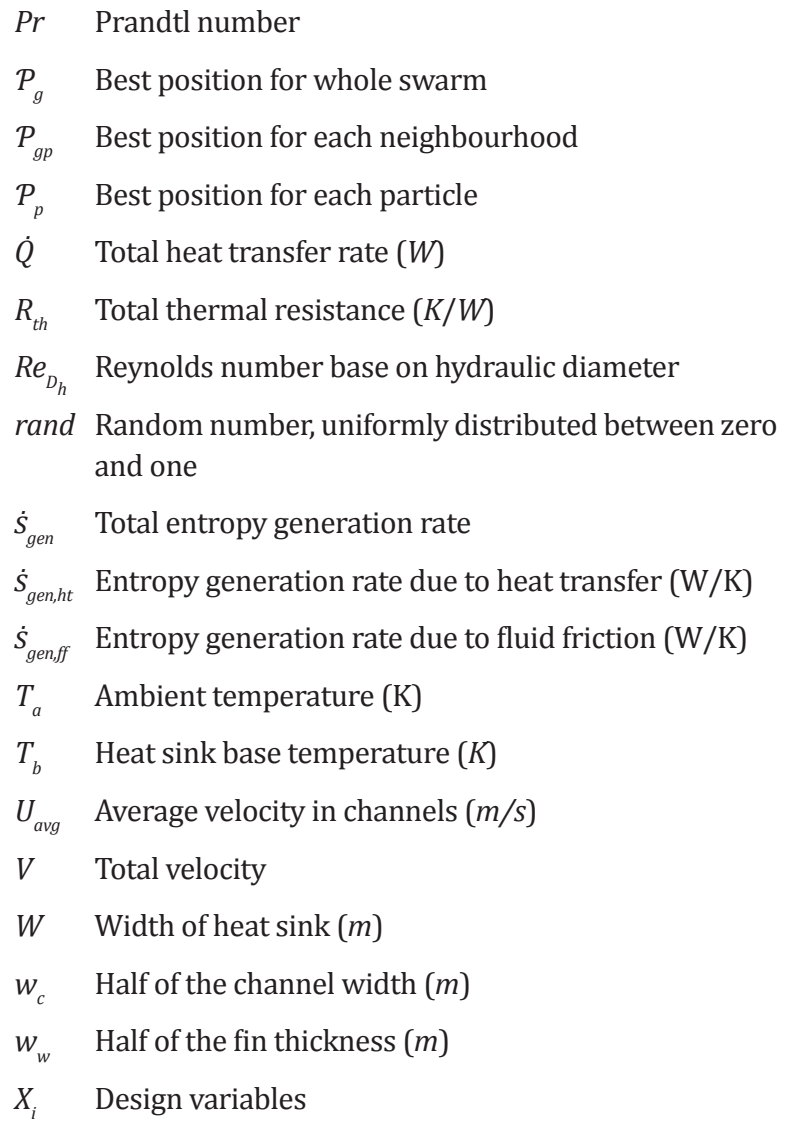

\section{Greek symbols}

$\begin{array}{ll}\alpha & \text { Slip parameter } \\ \alpha_{c} & \text { Channel aspect ratio } \equiv 2 w_{c} / H_{c} \\ \alpha_{h s} & \text { Heat sink aspect ratio } \equiv L / 2 w_{c} \\ \alpha_{t h} & \text { Thermal diffusivity } \equiv k_{-} f /|r h o| c d o t c_{-} p \\ & \left(\mathrm{~m}^{2} / \mathrm{s}\right) \\ \gamma & \text { Ratio of specific heats } \equiv c_{p} / c_{v} \\ \Delta P & \text { Pressure drop across microchannel }(\mathrm{Pa}) \\ \eta_{f i n} & \text { Fin efficiency } \\ v & \text { Kinematic viscosity of fluid }\left(\mathrm{m}^{\wedge} 2 / \mathrm{s}\right) \\ \rho & \text { Fluid density }\left(\mathrm{kg} / \mathrm{m}^{3}\right) \\ \sigma & \text { Tangential momentum accommodation coefficient } \\ \sigma_{t} & \text { Energy accommodation coefficient } \\ \varphi_{1} & \text { Cognitive parameter } \\ \varphi_{2} & \text { Social parameter } \\ \chi & \text { Constriction factor } \\ \Psi & \text { Swarm size }\end{array}$

\section{INTRODUCTION}

Modern electronics pack lots of semiconductors in a reduced area and execute specific tasks at high clock rates, magnifying the dissipated power and forcing designers to encompass heat transfer phenomena. What began with the era of Large Scale Integration (LSI) has led to different design strategies, and has produced different commercial options to deal with it.

Some years ago, Tuckerman and Pease urged the incorporation of heat sinks in electronics, since an inadequate thermal management leads to inefficiency and even failure of the devices. They considered an electric equivalent for designing microchannels and rocketed their use (nowadays, they are broadly used in microelectronics). Later, some researchers proposed an alternative design for microchannels, considering entropy generation as a metric of the irreversibility in a system (in a way that its minimisation represents the maximisation of the operating efficiency), but using traditional optimisation approaches. Recently, the use of the entropy generation minimisation (EGM) criterion has grown in different thermal management scenarios. We believe this is partly due to the evolution of modern optimisation and partly due to its straightforward application, Rao and Waghmare (2014), Hamadneh et al. (2013), Adham, MohdGhazali and Ahmad (2012), Mohammed Adham, Mohd-Ghazali and Ahmad (2013), Karathanassis et al. (2013), Chen and Chen (2013). However, these two (EGM and modern optimisation) have not been broadly applied to the design of microchannels until relatively recent years. For example, Adham, MohdGhazali and Ahmad (2014) used Genetic Algorithm (GA), and a modification of Khan's et al. model; and Khan, Kadri and Ali (2013) compared results achieved using GA against previously reported ones, obtained through NR. Additionally, Cruz, Amaya and Correa (2015) designed microchannel heat sinks with a more comprehensive mathematical model, using algorithms such as Simulated Annealing (SA), Unified Particle Swarm Optimisation (UPSO) and Spiral Optimisation. This article focuses on 


\section{Figure 1. Basic structure of a microchannel heat sink}

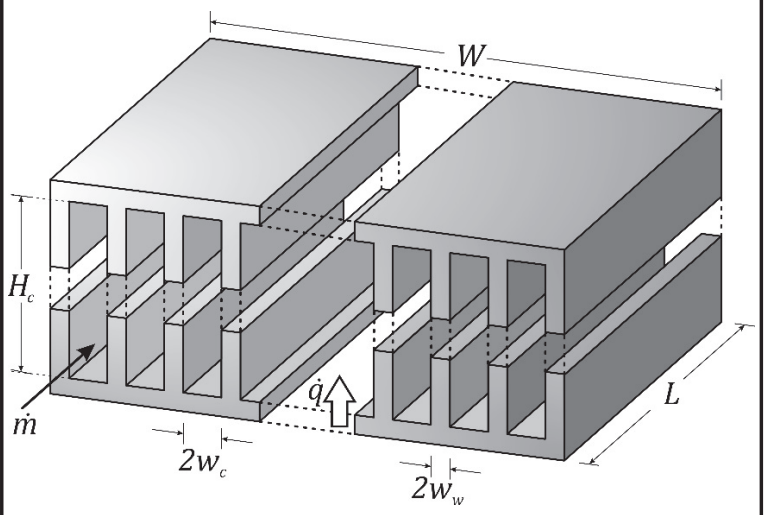

the aforementioned gap, designing a microchannel heat sink (MCHS) through entropy generation minimisation (EGM), and optimising it with two different modern techniques. From the vast supply of available methods, and for the need of a valid strategy to accomplish our designs in a short period of time and in a reliable way, we chose the Harmony Search (HS) and the Unified Particle Swarm Optimisation (UPSO) algorithms, due to their interesting characteristics, and to the good results they have achieved for different applications, Abdel-Raouf and Abdel-Baset Metwally (2013), Satpati, Koley and Datta (2014), Amaya, Cruz and Correa (2015). Furthermore we have already had good experience with those algorithms in other engineering applications. We begin by explaining some of the fundamentals around MCHS and about modern optimisation techniques, and then move on to the methodology section, where we discuss the procedure followed in this study. Moving on to the results, we first show the data of a Monte Carlo analysis and some preliminary tests with the algorithms, in order to obtain a first glance of the parameters and to define a set of values that allow both algorithms to achieve good results. Afterwards, we compare the performance of HS and UPSO under specific scenarios, and for multiple materials and heat generation configurations. We finish this manuscript through the conclusions and recommendations for future research.

\section{FUNDAMENTALS}

Nowadays, integrated circuits (IC) are fabricated using vast amounts of semiconductors so that they can operate at high frequencies. However, the power dissipated by a chip increases with the operating frequency, and since their performance is temperature sensitive, it is vital to remove it. Heat sinks provide a thermal support to electronic devices, allowing the heat to flow from the device and to the environment, and thus extending their lifetime.

\subsection{Model of the microchannel heat sink}

Heat sinks may have diverse geometries, but they all perform the same task and are based on the same main principle: extended superficial area available for heat transfer. Among them, microchannel heat sinks (MCHS) are commonly used when space, temperature and heat flux are constrained by the specification of the problem (e.g. biomedical systems, laptops and gadgets). The main features of these devices relate to their base structure (which confines a fluid flow to channels and thus allows a high heat transfer flux), as well as, to their small temperature increase, high heat transfer coefficients and negligible effects related to mass transfer. MCHS have been broadly used in literature, Rimbault, Nguyen and Galanis (2014), Karunanithi and Hassanipour (2014), Hatami and Ganji (2014), Leng et al. (2015), Hajialigol et al. (2015), Khan, Kadri and Ali (2013), Adham, Mohd-Ghazali and Ahmad (2014). A general scheme of their base structure is shown in Figure 1 where the geometric parameters $L$ and $W$ relate to the length and width of the device, respectively; $H_{c}$ and $w_{c}$ represent the height and half-width of each channel; and $w_{w}$ is half the separation between two channels.

In order to obtain the mathematical model, Khan et al. (2013) considered the top surface as adiabatic, while the lower plate allowed for a uniform heat flow from the chip. They assumed that the walls of the channels are smooth and with adiabatic extremes, and that the material of the heat sink is isotropic. Both, the cooling fluid and the thermal energy flow, are considered as stationary, laminar, 
two-dimensional and fully developed. The effects due to fluid drag can be overlooked when $0.001 \leq K n \leq 0.1$. Moreover, the flow is uncompressible with constant thermophysical properties and the axial conduction of the fin and the fluid is neglected, as well as the variations of kinetic and potential energies. This model also assumes an equal area available for heat transfer, between the microchannel and the electronic device. This last aspect seems a rather particular limitation of this model, due that it is not a common situation in real life. Khan et al. developed the model shown in (1), which describes the entropy generation rate of a MCHS. This equation correlates the entropy generated due to the irreversibility of heat transfer (in the heat sink and in the fluid) and to the fluid friction, defined as $\dot{S}_{g e n, h t}$ and $\dot{S}_{g e n, f f}$, respectively. This correlation was obtained through the methodology laid out by Bejan (1995) who dictates that the minimum entropy generation of a real system can be found through an analysis based on heat transfer, fluid mechanics and thermodynamics,

$$
\begin{gathered}
\dot{S}_{g e n}=\dot{S}_{g e n, h t}+\dot{S}_{g e n, f f}=\frac{\dot{Q}^{2}}{T_{a} T_{b}} R_{t h}+\frac{G}{T_{a}} \Delta P= \\
\frac{\dot{Q}^{2}}{T_{a} T_{b}}\left(\frac{2 \alpha_{h s} C_{3}}{L k_{f} C_{1} C_{2}}\right)+\frac{N \rho w_{c} H_{c} U_{\text {avg }}^{3} C_{4}}{T_{a}}
\end{gathered}
$$

The first part of the entropy generation, $\dot{S}_{g e n, h t}$, depends on the heat transfer rate $(\dot{Q})$, as well as on the absolute temperature of the base plate $\left(T_{b}\right)$ and of the ambient $\left(T_{a}\right)$, and the total thermal resistance of the device. The latter relates to a correlation of parameters: $\left(2 \alpha_{h s} C_{3}\right) /\left(L k_{f} C_{1} C_{2}\right)$, where $\alpha_{h s}$ and $L$ are the aspect ratio and the length (in the direction of the heat flow). $k_{f}$ is the thermal conductivity of the fluid and $C_{1}$, $\mathrm{C}_{2}$ and $C_{3}$ are correlations of the number of channels $\left(N=\left(W / 2-2 w_{w}\right) /\left(w_{c}+w_{w}\right)\right)$, the aspect ratio of the heat sink and the channel $\left(\alpha_{h s}=L / 2 w_{c}\right.$ and $\alpha_{c}=2 w_{c} / H_{c}$, respectively), the fin's efficiency $\left(\eta_{f i n}\right)$, and dimensionless groups such as Nusselt's $\left(N u_{D_{h}}\right)$ and Peclet's $\left(P e_{D_{h}}\right)$ numbers, shown in (2),

$$
C_{1}=N \alpha_{h s}\left(2 \eta_{f i n}+\alpha_{c}\right), C_{2}=\frac{1+\alpha_{c}}{\alpha_{c}}, C_{3}=\frac{1}{N u_{D_{h}}}+\frac{C_{1}}{N \cdot P e_{D_{h}}}
$$

The second part of the entropy generation, $\dot{s}_{\text {gen,ff }}$ depends on $N$ and $T_{a^{\prime}}$ as well as on the fluid density $(\rho)$, the channel geometry $\left(w_{c}\right.$ and $\left.H_{c}\right)$, the average velocity of the flow $\left(U_{\text {avg }}\right)$ and the parameter $C_{4}$, that correlates the losses on the channels with the effects due to friction, as shown in (3).

$C_{4}=k_{c e}+f\left(\frac{\mathrm{L}}{D_{h}}\right)$

Once a single-objective function based on (1) has been defined, the heat sink is designed by finding the variables (i.e. the design vector) $H_{c^{\prime}}, w_{c}, w_{w^{\prime}} K n$ and $G$ that minimise the entropy generation rate. Thus, the restricted optimisation problem given in (4) appears. For this research, we also considered, for comparison purposes, the restrictions previously reported in literature Adham, Mohd-Ghazali and Ahmad (2012).

$$
\begin{array}{ll}
\min \dot{S}_{g e n}=\min \left\{\frac{\dot{Q}^{2}}{T_{a} T_{b}} \frac{2 \alpha_{h s} C_{3}}{L k_{f} C_{1} C_{2}}+\frac{N \rho w_{c} H_{c} U_{\text {avg }}^{3} C_{4}}{T_{a}}\right\} \\
\text { s.t } \quad 2 w_{c} \leq H_{c} \text { and } w_{w} \leq w_{c} \\
& 1 \mu \mathrm{m} \leq H_{c} \leq 50 \mathrm{~mm} \\
& 1 \mu \mathrm{m} \leq w_{c}, w_{w} \leq 1 \mathrm{~mm} \\
& 0.001 \leq K n \leq 0.1 \\
& 1 \times 10^{-6} \mathrm{~m}^{3} / \mathrm{s} \leq G \leq 0.01 \mathrm{~m}^{3} / \mathrm{s}
\end{array}
$$

\subsection{Modern global optimization methods}

These techniques generally require simple calculations, making them versatile and easy to implement, as opposed to traditional gradient-based approaches.

\section{Harmony Search algorithm (HS)}

About fifteen years ago, as presented Amaya, et al. (2015), Geen proposed the HS algorithm inspired by the improvisation expert musicians carry out. This process is modelled through three possible choices regarding a piece of music: reproduce an already famous one, a variant or a brand new one. Since a piece of music is a sequence of tones playing in harmony, HS relates them to the design vector of an optimisation problem. In its most basic form, HS depends on four parameters. The first one is the Harmony Memory Size 
(MHS), or simply put, the maximum number of pieces that can be stored in memory. The second parameter is the Harmony Memory Considering Rate (HMCR), that determines if an already stored piece should be selected, or not. The third parameter is the Pitch Adjusting Rate (PAR) and defines how often a selected piece must be adjusted using (5) and the fourth parameter, known as Fretwidth $(F W)$. The modified solution, $X_{t}^{\prime}$, is the same piece that was selected, but shifted around $F W$, using a uniformly distributed random number between zero and one (rand). It is worth mentioning that this is the only equation HS requires, as opposed to other approaches,

$X_{t}^{\prime}=X_{t}^{\prime}+(2 \cdot$ rand -1$) \cdot F W$.

A general algorithm can thus be laid out as:

1. Define $H M C R, P A R, F W$, the search domain $X_{\min } \leq X \leq X_{\max }$, and the objective function $f_{o b j}\left(X_{1}\right.$, $\left.X_{2}, \ldots, X_{n}\right)$. Also, define the stop criteria.

2. Randomly populate the memory matrix $(H M)$, of size $H M S \times n$.

3. Generate a random number with HMCR probability of being successful. If it is, go to step four. Otherwise, select a random value and go to step six.

4. Select the element located at a random row of $H M$ and at the column corresponding to the dimension being updated.

5. Generate a random number with $P A R$ probability of being successful. If it is, update the value using (5).

6. Move on to the next dimension and repeat for all $n$ dimensions.

7. Check stop criteria. If it complies, stop and print results. Otherwise, return to step three.

Unified Particle Swarm Optimisation algorithm (UPSO)

UPSO was proposed by Parsopoulos and Vrahatis, and it is an improvement of the traditional PSO algorithm, originally proposed by Kennedy and Eberhart. This technique is based on swarm intelligence and it was inspired by the natural process of food search carried out by bird flocks and fish shoals. The main difference between UPSO and PSO is that in the former, the agents (also known as particles) can form subsets (or neighbourhoods), in order to strengthen the exploration (global behaviour) and exploitation (local behaviour) of the search domain. The total velocity of a particle is composed of a global and a local dynamic, respectively known as $\mathcal{G}$, (6), and $\mathcal{L}$, (7),

$\mathcal{G}_{p}^{t+1}=\chi \cdot\left[V_{p}^{t}+\varphi_{1} \operatorname{rand}_{1}\left(P_{p}-\chi_{p}^{t}\right)+\varphi_{2} \operatorname{rand}_{2}\left(P_{g}-\chi_{p}^{t}\right)\right]$

$\mathcal{L}_{p}^{t+1}=\chi \cdot\left[V_{p}^{t}+\varphi_{1} \operatorname{rand}_{3}\left(P_{p}-\chi_{p}^{t}\right)+\varphi_{2} \operatorname{rand}_{4}\left(P_{g p}-\chi_{p}^{t}\right)\right]$

These two elements directly depend on parameters such as the constriction factor, $\chi$, that limits the velocity of the particles to avoid an explosion of the swarm; the self and swarm confidence, $\varphi_{1}$ and $\varphi_{2}$ respectively; and four uniformly distributed random numbers between zero and one, rand ${ }_{1}$. UPSO also considers the position, $\chi_{p}^{t}$, and the total velocity, $V_{p}^{t}$, at the time step $t$, as well as the best position found by each particle, $P_{p}$, by each neighbourhood, $P_{g p}$ and by the swarm, $P_{g}$ , during the whole search. Note that the index $p$ relates to a particle in the swarm, where $p=1, \ldots, \Psi$, and $\Psi$ is the total number of agents. The total velocity of each particle for the next time step, $V_{p}^{t+1}$, is obtained through (8) where $u$ is the unification factor and represents a constant between zero and one, whose objective is to balance the global and local behaviour of each particle. Finally, (9) is used to find the new position of the swarm,

$V_{p}^{t+1}=(1-u) \mathcal{L}_{p}^{t+1}+u \cdot \mathcal{G}_{p}^{t+1}$

$\chi_{p}^{t+1}=\chi_{p}^{t+1}+V_{p}^{t+1}$

A general algorithm can thus be laid out as:

1. Define $\chi, \varphi_{1}, \varphi_{1}, \Psi$ and the selection criteria of the neighbourhoods, the search domain $X_{\min } \leq X_{p} \leq X_{\max }$ , and the objective function $f_{o b j}(\chi)$.

2. Randomly assign the initial position of each particle, $\chi_{p}^{1}$, over the search domain and assign an initial value for the velocity $V_{p}^{1}$. 
3. Evaluate each position, $\chi_{\mathrm{p}}$, in $f_{o b j}$ and find $\mathcal{P}_{p}, P_{g p}$ and $P_{g^{\prime}}$

4. Use (8) and (9) to calculate $\chi_{p}^{t+1}$ and $V_{p}^{t+1}$, respectively.

5. Evaluate each new position in the objective function and update $P_{p}, P_{g p}$ and $P_{g}$.

6. Check stop criteria. If it complies, stop and print results. Otherwise, make $t=t+1$ and go to step four.

\subsection{Solution of a constrained}

\section{optimisation problem}

A constrained optimisation problem is defined as shown in (10), and the design vector $\chi^{*}$ with $n$ components is known as the solution, or optimum design variable, which represents the design vector $\chi$ that minimises the single-objective function $f_{o b j}(\chi)$ inside the feasible region defined by the restrictions $g_{i}$ and the boundaries of each dimension. Any number of restrictions, $n_{g}$, can be implemented and they might represent either equalities or inequalities,

$$
\begin{gathered}
\min f_{o b j}(X), X=\left\{X_{1}, X_{2}, \ldots, X_{n}\right\} \forall X \in \mathbb{R}^{n} \\
\text { s.t. } g_{i}(X) \leq 0 \quad \forall i=1,2, \ldots, n_{g} \\
\left.X_{j, \text { lower }} \leq X_{j} \leq X_{j, \text { upper }} \forall j=1,2, \ldots, n\right)
\end{gathered}
$$

There are, at least, two general approaches for solving these kind of problems through global optimisation algorithms. The first one repositions the agents into the feasible region whenever an update takes them out, and the kind of reposition varies according to the optimisation algorithm. The second one modifies the objective function through penalty factors, which in turn vary according to each specific problem.

\section{METHODOLOGY}

During this study, simulation data was gathered using an ASUS $®$ S46C personal computer with the following specifications: Intel ${ }^{\circledR}$ Core $^{\mathrm{TM}}$ i7-3537U CPU @ $2.00 \mathrm{GHz}-2.50 \mathrm{GHz}, 6 \mathrm{~GB}$ RAM, operating under Microsoft@ Windows ${ }^{\mathrm{TM}} 8.1$ Single - 64 bits. This work was split into different stages, and in all tests we stopped the algorithms if they did not improve after a given number of iterations (saturation) or if excessive iterations were carried out.

\subsection{Monte Carlo simulation}

The first stage was a set of Monte Carlo simulations to observe the relative importance of the design parameters, from a known distribution of entropy generation rate, and the influence of heat and mass transfer phenomena on it. We first analysed the final equation and then began deepening into the definition of each variable, via their respective equations. For each one of these tests, $10^{10}$ samples were generated so the data was significant.

\subsection{Selection of parameters}

The second stage was a parameter search to tune each algorithm, so their performances could be properly addressed. On this regard, we used the design parameters shown in Table 1, considering air as cooling fluid and a total heat transfer of $150 \mathrm{~W}$ from the chip. We also used the set of parameters shown in Table 2, and ran 40 repetitions of each parameter configuration, for each algorithm, considering the objective function given in (1), and the design vector as $X=\left(H_{c}, w_{c}, w_{w}, K n, G\right)$ all this in order to solve the minimisation problem given in (4). We measured the convergence rate of each configuration, which is simply the ratio of the tests that satisfied the main stop criterion, over the total number of tests. It is worth mentioning that we used three different components for the fretwidth (FW1, FW2 and $F W 3$ ), where each one relates to a specific design variable. This was done because there is a difference in the order of magnitude of the design variables and because a bad scaling of $F W$ could jeopardize HS's performance. After finding the best parameters for each algorithm, 1000 repetitions were run for each one and we analysed their benefits and drawbacks.

We also performed the Wilcoxon signed-rank test for the difference of $\dot{s}_{\text {gen,min }}$ obtained through HS 
Table 1. Assumed values to calculate entropy generation rate for a microchannel heat sink.

\begin{tabular}{l|l|l|l}
\hline Parameter & Value & Parameter & Values \\
\hline$L(\mathrm{~mm})$ & 51 & $\operatorname{lnu}\left(\mathrm{m}^{2} / \mathrm{s}\right)$ & $1.58 \times 10^{-5}$ \\
\hline$W(\mathrm{~mm})$ & 51 & $\operatorname{Pr}$ & 0.71 \\
\hline$k(\mathrm{~W} / \mathrm{m} \cdot K)$ & 398 & $\dot{Q}(\mathrm{~W})$ & 150 \\
\hline$k_{f}(\mathrm{~W} / \mathrm{m} \cdot K)$ & 0.0261 & $T_{a}(K)$ & 300 \\
\hline$\rho\left(\mathrm{kg} / \mathrm{m}^{3}\right)$ & 1.1614 & $\sigma$ & 0.85 \\
\hline$c_{p}(\mathrm{~J} / \mathrm{kg} \cdot K)$ & 1007 & $\sigma_{t}$ & 0.85 \\
\hline
\end{tabular}

\begin{tabular}{l}
\multicolumn{2}{|c|}{$\begin{array}{c}\text { Table 2. Set of parameters for HS and UPSO during } \\
\text { the tuning stage. }\end{array}$} \\
\hline \begin{tabular}{l|l} 
Parameters & Values \\
\hline$\psi_{\text {and } H M S}$ & $10,25,50,75,100,125,175$ and 200 \\
\hline$\varphi_{1}$ and $\varphi_{2}$ & $2.0,2.2,2.4,2.6,2.8$ and 3.0 \\
\hline$\chi$ & $0.1,0.4$ and 0.7 \\
\hline$u, H M C R$ and $P A R$ & $0.2,0.4,0.6,0.8,0.9,0.95$ and 0.99 \\
\hline$F W 1$ & $\left\langle 10^{-6}, 10^{-7}, 10^{-7}, 10^{-4}, 10^{-7}\right\rangle$ \\
\hline$F W 2$ & $\left\langle 10^{-5}, 10^{-6}, 10^{-6}, 10^{-3}, 10^{-6}\right\rangle$ \\
\hline$F W 3$ & $\left\langle 5 \times 10^{-5}, 10^{-5}, 10^{-6}, 10^{-2}, 10^{-5}\right\rangle$ \\
\hline
\end{tabular} \\
\hline
\end{tabular}

\section{Table 3. Materials considered to design a MCHS and their thermal conductivities.}

\begin{tabular}{l|c|l|c}
\hline Material & $\boldsymbol{k}(\boldsymbol{W} / \boldsymbol{m} \cdot \boldsymbol{K})$ & Material & $\boldsymbol{k}(\boldsymbol{W} / \boldsymbol{m} \cdot \boldsymbol{K})$ \\
\hline $\begin{array}{l}\text { Molybdenum } \\
(\text { Mo) }\end{array}$ & 142 & $\begin{array}{l}\text { Silicon } \\
\text { carbide (SiC) }\end{array}$ & 270 \\
\hline Tungsten (W) & 155 & Gold (Au) & 315 \\
\hline $\begin{array}{l}\text { Aluminum } \\
\text { (Al) }\end{array}$ & 247 & $\begin{array}{l}\text { Aluminum } \\
\text { nitride (AIN) }\end{array}$ & 320 \\
\hline $\begin{array}{l}\text { Beryllium } \\
\text { oxide }(\mathrm{BeO})\end{array}$ & 260 & Copper (Cu) & 398 \\
\hline
\end{tabular}

and UPSO, using equality of mean values as the null hypothesis $\left(\mathcal{H}_{0}: \mu_{H S}=\mu_{\text {UPSO }}\right)$ and a significance level of 0.05 for two tails Derrac et al. (2011).

\subsection{Design scenarios}

The third stage considered two variations of the model and its constraints. We analyse the solutions

and the way in which the algorithms behaved. The first one dealt with bigger search domains, but preserving the context of the design, as shown in (11). Here, it is important to note that the limits of $K n$ were not varied since the effects due to fluid drag were disregarded. The second one dealt with different materials (Table 3 ), based on the information provided in Mohammed Adham, Mohd-Ghazali and Ahmad (2013) for microchannel structures, and with different heat generation rates $(\dot{Q})$,

$$
\begin{aligned}
& 2 w_{c} \leq H_{c} \text { and } w_{c} \geq w_{w} \\
& 10^{-10} \leq H_{c} \leq 50 \times 10^{-3} \mathrm{~m} \\
& 10^{-10} \leq w_{c} \leq 10^{-3} \mathrm{~m} \\
& 10^{-10} \leq w_{w} \leq 10 \times 10^{-3} \mathrm{~m} \\
& 0.001 \leq \mathrm{Kn} \leq 0.1 \\
& 10^{-10} \leq \mathrm{G} \leq 10^{-2} \mathrm{~m}^{3} / \mathrm{s}
\end{aligned}
$$

\subsection{Data Comparison}

In the final stage of this work, $K n$ as well as $G$, were fixed in an interval, as shown by the constraints given in (12). A material with $k=148 \mathrm{~W} / \mathrm{m} \cdot \mathrm{K}$ was also considered. The resulting designs were compared with some of the data provided by Khan, Kadri and Ali (2013),

$$
\begin{aligned}
& 2 w_{c} \leq H_{c} \text { and } w_{c} \geq w_{w} \\
& 3 \leq H_{c} \leq 8 \mathrm{~mm} \\
& 0.1 \leq 2 w_{c}, 2 w_{w} \leq 0.3 \mathrm{~mm} \\
& 0.001 \leq K n \leq 0.1 \\
& 0.005 \leq G \leq 0.009 \mathrm{~m}^{3} / \mathrm{s}
\end{aligned}
$$

\section{RESULTS AND DISCUSSION}

\subsection{Monte Carlo analysis}

Table 4 shows the values found with Monte Carlo, which provides us with an insight about the order of magnitude of each parameter and their relative importance. In this case, we obtained a feasible MCHS design (choosing each parameter from the intervals given in Table 4), but not the optimum one.

\subsection{Parameter selection}




\begin{tabular}{|c|c|c|c|}
\hline Parameter & Min. value & Max. value & Unit \\
\hline$\dot{S}_{g e n}$ & 0.4340 & 0.4459 & $W / K$ \\
\hline$\dot{S}_{g e n, f f}$ & 0.0367 & 0.0373 & $W / K$ \\
\hline$\dot{S}_{g e n, h t}$ & 0.3973 & 0.4086 & $W / K$ \\
\hline$R_{t h}$ & 0.3387 & 0.3527 & $K / W$ \\
\hline$\Delta P$ & 1573.6436 & 1599.3707 & $\mathrm{~Pa}$ \\
\hline U_\{avg\} & 2.7793 & 3.5731 & $\mathrm{~m} / \mathrm{s}$ \\
\hline$H_{c}$ & $173.39 \times 10^{-4}$ & $1.0327 \times 10^{-1}$ & $m$ \\
\hline$w_{c}$ & $8.2103 \times 10^{-5}$ & $8.4662 \times 10^{-5}$ & $m$ \\
\hline$w_{w}$ & $8.9911 \times 10^{-8}$ & $8.2103 \times 10^{-5}$ & $m$ \\
\hline
\end{tabular}

When using HS, it was found that a reduced memory size (HMS) and a high considering rate (HMCR) yielded a high convergence rate (Figure 2a). Regarding the pitch rate $(P A R)$, we found that smaller values tended to favour convergence for almost all $H M S$ values (Figure $\mathbf{2 b}$ ) as well as for every $H M C R$, even though in the latter the effect was more important for lower values (Figure 3a). The remaining parameter, i.e. the fretwidth $(F W)$, provided an improvement in the average convergence rate when using the first configuration, even though its effect was not as strong as for the other ones (Figure 3b). Therefore, we selected 10, 0.9, 0.2 and FW3 as the values for HMS, HMCR, PAR and FW.

\section{Figure 2. Average convergence rates found when varying (A) HMS and HMCR, and (B) HMS and PAR}

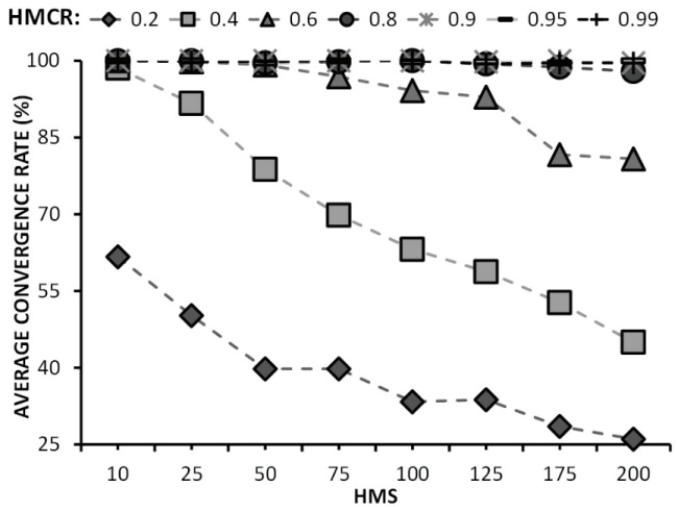

(A)

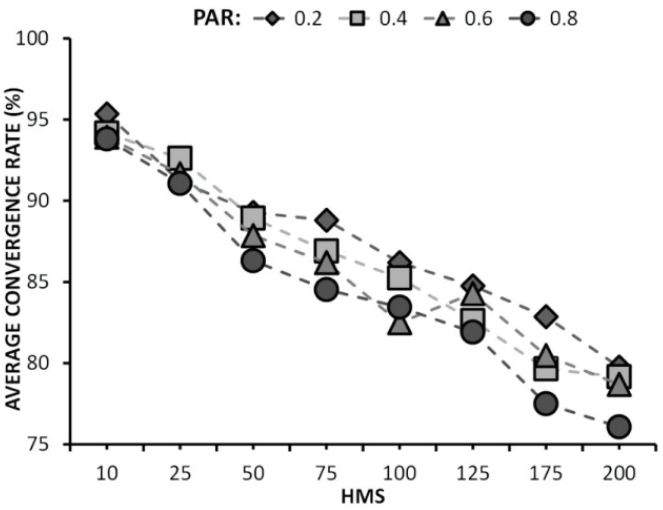

(B)

Figure 3. Average convergence rates found when varying (A) HMCR and $P A R$, and (B) HMS and FW

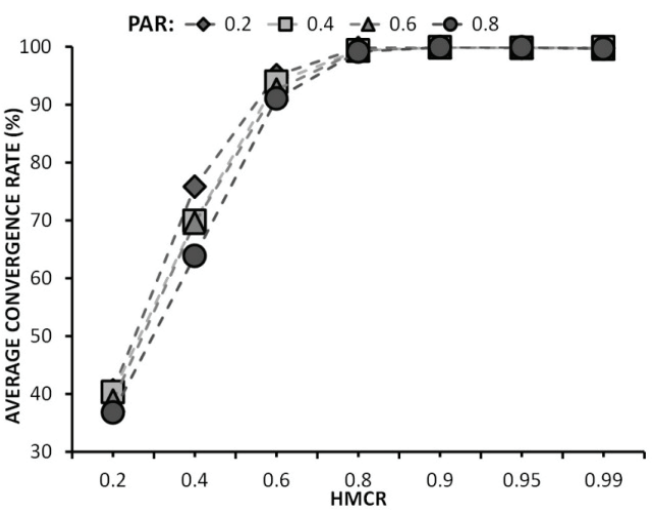

(A)

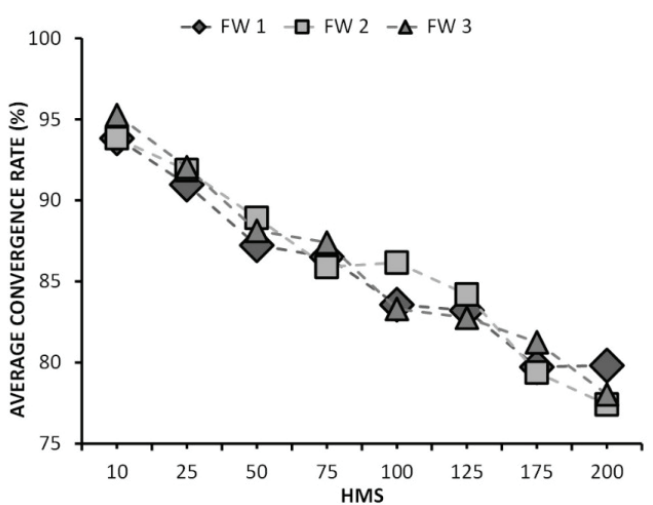

(B) 
Figure 4. Average convergence rates found when varying (A) $\psi$ (or swarm size) and $u$, and (B) $\psi$ (or swarm size) and $x$ (or chi)

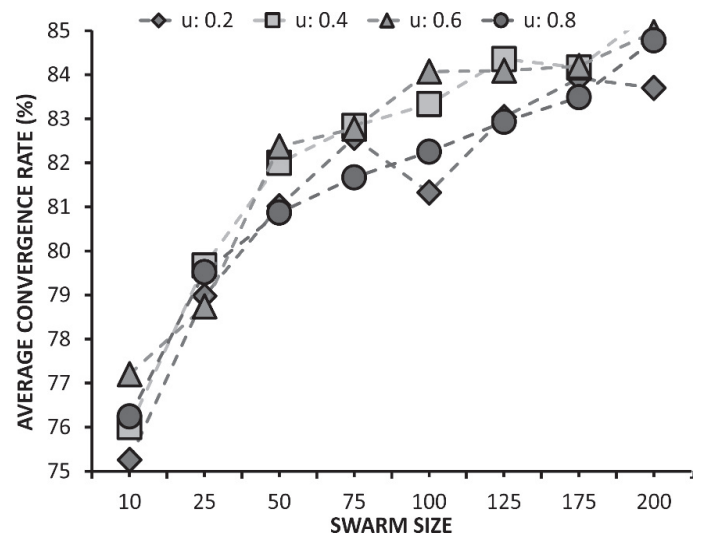

(A)

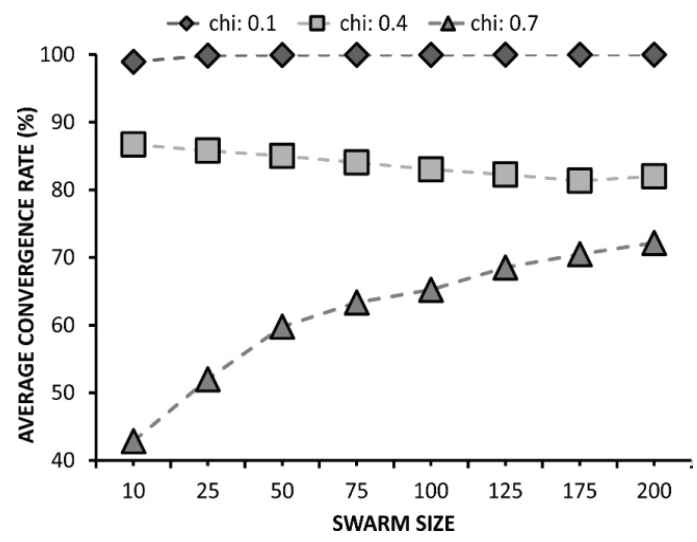

(B)
Figure 5. Average convergence rates found when varying $\varphi_{1}$ (or phi1) and $\varphi_{2}$ (or phi2).

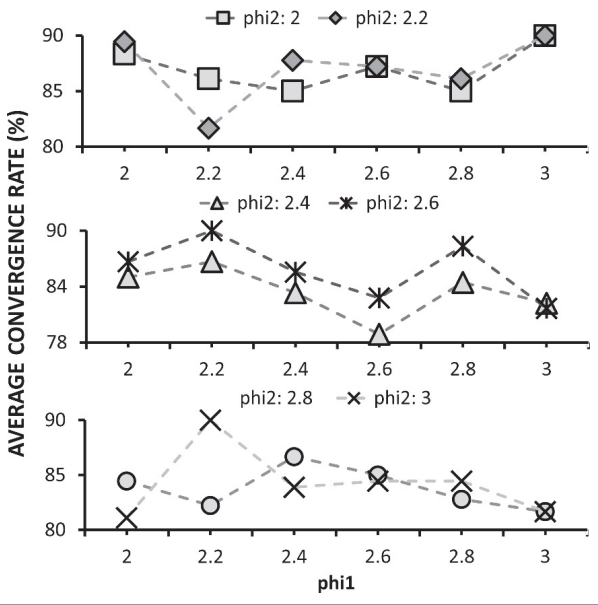

With respect to UPSO, we found that bigger swarms and a unification factor $(u)$ between 0.4 and 0.6 yielded better convergence rates (Figure 4a). In order to clarify this idea some more, we calculated a global convergence rate, considering the average of all tests (including all combinations of parameters) as a function of the unification factor. We found that $u=0.4$ and $u=0.6$ yield $82.2 \%$ and $82.3 \%$, respectively, while $u=0.2$ yields $81.2 \%$ and $u=0.8$ yields $81.5 \%$. We also found that no matter the size of the swarm, smaller constriction values $(\chi)$ provide better convergence rates (Figure $\mathbf{4 b}$ ). Since $\varphi_{1}$ and $\varphi_{2}$ are both part of the same equation, we looked for a good combination and not for a tendency, finding that $\varphi_{1}=3.0$ and $\varphi_{1}=2.2$ yielded the highest convergence rates (Figure 5).

Table 5 summarizes the parameters that work best for both algorithms, based on what was previously discussed and the best results achieved with each algorithm are laid out in Table 6. Figure 6 shows the normalised frequency distribution for the minimum entropy generation rates found with HS and UPSO, using the same bins for both techniques (calculated using UPSO's span). In the first case, we considered only 959 executions in the plot, striving to simplify the plot. We noted that the probability of obtaining a $\dot{s}_{g e n, \min }$ between 32.26 and $33.68 \mathrm{~mW} / \mathrm{K}$ using HS and UPSO is of $23.5 \%$ and of $9.6 \%$, respectively. Also, we found that the mean value of $\dot{s}_{g e n, \min }$ is virtually the same for both methods, but HS showed a standard deviation of $5 \mathrm{~mW} / \mathrm{K}$, more than twice that of UPSO's; and HS requires almost five times more iterations than UPSO, but it does them in a time about 20 times smaller.

\begin{tabular}{|c|c|c|c|}
\hline$H S$ & & UPSO & \\
\hline Parameters & Values & Parameters & Values \\
\hline HMS & 10 & $\psi$ & 200 \\
\hline$H M C R$ & 0.9 & $u$ & 0.5 \\
\hline$P A R$ & 0.2 & $\varphi 1$ & 3.0 \\
\hline \multirow[t]{2}{*}{$F W$} & FW3 & $\varphi 2$ & 2.2 \\
\hline & & $x$ & 0.1 \\
\hline
\end{tabular}




\begin{tabular}{|c|c|c|}
\hline \multicolumn{3}{|c|}{$\begin{array}{c}\text { Table 6. Summary of best design parameters foun } \\
\text { with HS and upso after } 1000 \text { repetitions, } \\
\text { using the original constraints }\end{array}$} \\
\hline Design parameters & HS & UPSO \\
\hline$\dot{S}_{g e n, \min }(W / K)$ & 0.032011 & 0.032257 \\
\hline$H_{c}(\mathrm{~mm})$ & 49.8 & 48.7 \\
\hline$w_{c}(\mu m)$ & 168 & 180 \\
\hline$w_{w}(\mu m)$ & 69.2 & 67.6 \\
\hline$K n$ & $1.64 \times 10^{-2}$ & $5.49 \times 10^{-3}$ \\
\hline$G\left(m^{3} / s\right)$ & $9.98 \times 10^{-3}$ & $9.87 \times 10^{-3}$ \\
\hline
\end{tabular}

Figure 6. Normalised frequency distribution for the minimum entropy generation rates found with HS and UPSO after 1000 repetitions.

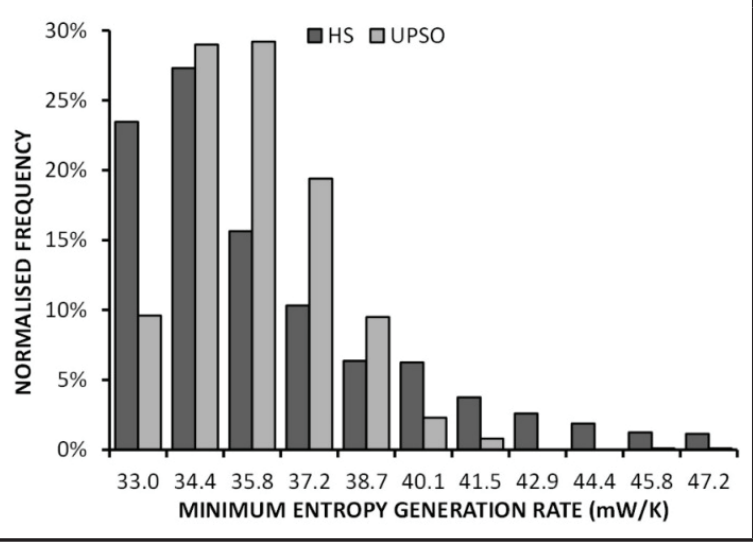

Figure 7. Normalised frequency distribution for the difference of minimum entropy generation rates found by HS and by UPSO after 1000 repetitions.

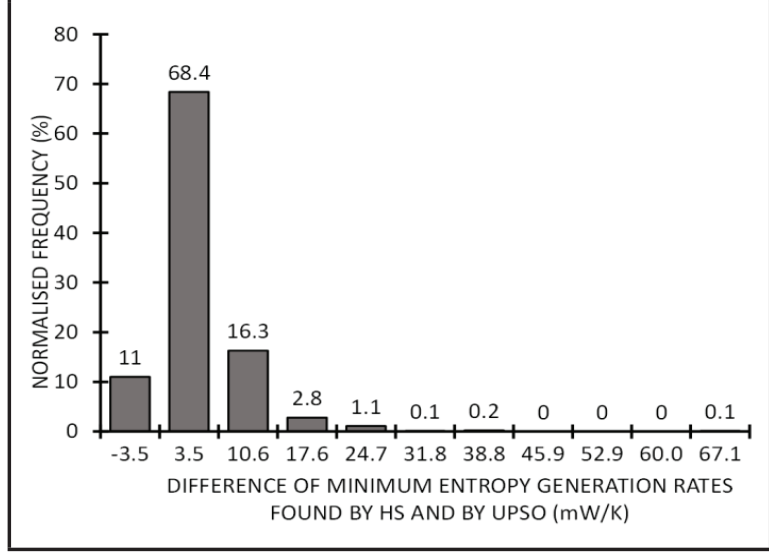

In addition, the Wilcoxon signed-rank test, a non-parametric statistical hypothesis test, was used to compare the difference of $\dot{S}_{g e n, \min }$ obtained using both methods (i.e., HS and UPSO). It was concluded that there is insufficient evidence to reject the null hypothesis $\left(\mathcal{H}_{0}: \mu_{H S}=\mu_{U P S O}\right)$, with a significance level of 0.05 . The power of the test was 0.1912 . Figure 7 shows the distribution of this difference with mean, standard deviation, skewness and kurtosis equal to $0.89 \mathrm{~mW} / \mathrm{K}, 5.34 \mathrm{~mW} / \mathrm{K}, 3.52$ and 28.67,respectively.

\subsection{Design scenarios}

\subsubsection{Search domain expansion}

After expanding the search domain, both approaches achieved minimum entropy values quite similar to those of the smaller domain (Table 7), although the values of the design parameters are somewhat different. Even so, we found that the average minimum entropy generation rate increased for both algorithms and that the big data dispersion of HS is still present (Table 8).

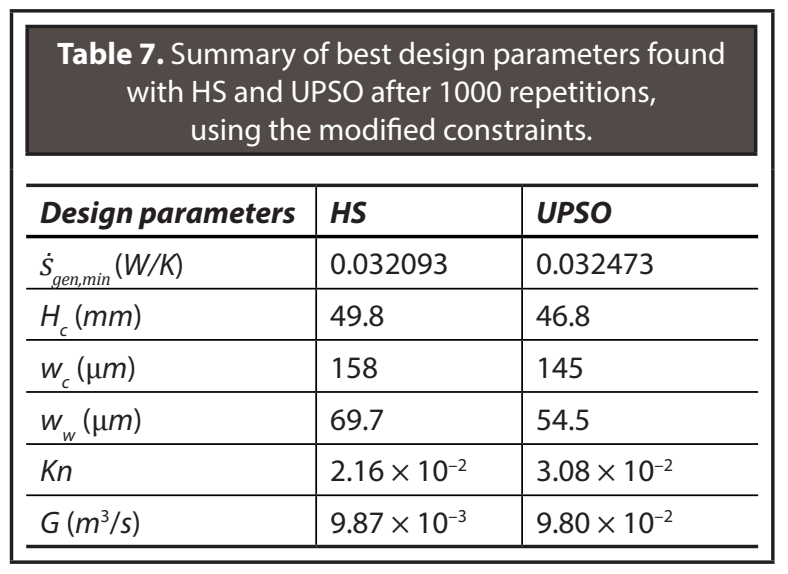

\begin{tabular}{|c|c|c|c|c|c|c|}
\hline & \multicolumn{6}{|c|}{$\begin{array}{l}\text { Table 8. Summary about } 1000 \text { repetitions } \\
\text { of HS and UPSO using the parameters given } \\
\text { in Table } 5 \text { and the modified constraints (11). }\end{array}$} \\
\hline & $\begin{array}{l}\text { HS } \\
\dot{S}_{\text {gen,min }} \\
(W / K)\end{array}$ & Iterations & $\begin{array}{l}\text { Time } \\
\text { (s) }\end{array}$ & $\begin{array}{l}\text { UPSO } \\
\dot{S}_{g e n, \min } \\
(W / K)\end{array}$ & Iterations & $\begin{array}{l}\text { Time } \\
\text { (s) }\end{array}$ \\
\hline Mean & 0.0369 & 111 & 1.6980 & 0.0359 & 21 & 0.7141 \\
\hline $\begin{array}{l}\text { Std } \\
\text { dev }\end{array}$ & 0.0046 & 52 & 0.8784 & 0.0018 & 9 & 0.3097 \\
\hline Min & 0.0321 & 11 & 0.0408 & 0.0325 & 10 & 0.2091 \\
\hline Max & 0.0881 & 455 & 6.9756 & 0.0434 & 111 & 2.7942 \\
\hline
\end{tabular}


Table 9. Optimal MCHS's design found with HS for different materials.

\begin{tabular}{c|l|l|l|l|l}
\hline & $\begin{array}{l}H_{c} \\
(m) \\
10^{-3}\end{array}$ & $\begin{array}{l}W_{c} \\
(m) \\
10^{-6}\end{array}$ & $\begin{array}{l}W_{w} \\
(m) \\
10^{-6}\end{array}$ & $\begin{array}{l}K n \\
10^{-3}\end{array}$ & $\begin{array}{l}G \\
\left(\mathrm{~m}^{3} / \mathrm{s}\right) \\
10^{-3}\end{array}$ \\
\hline $\mathrm{Mo}$ & 49.7 & 148.1 & 80.8 & 22.3 & 9.9 \\
\hline $\mathrm{W}$ & 49.0 & 132.8 & 66.6 & 33.4 & 9.9 \\
\hline $\mathrm{Al}$ & 49.6 & 142.9 & 63.1 & 25.2 & 10.0 \\
\hline $\mathrm{BeO}$ & 49.0 & 160.5 & 62.7 & 15.0 & 10.0 \\
\hline $\mathrm{SiC}$ & 49.9 & 162.5 & 61.4 & 16.1 & 10.0 \\
\hline $\mathrm{Au}$ & 49.9 & 165.1 & 69.0 & 18.1 & 9.9 \\
\hline $\mathrm{AIN}$ & 49.2 & 157.0 & 74.6 & 21.5 & 9.9 \\
\hline $\mathrm{Cu}$ & 49.5 & 172.4 & 79.1 & 15.9 & 9.9 \\
\hline
\end{tabular}

\subsubsection{Tests for different materialls}

We found that the convergence rate of both approaches is not affected by the material which the heat sinks are made of, since higher conductivity values returned lower entropy generation rates, as expected (Table 9). Nevertheless, there is a clear dependence of the values of the design parameters with that variable. In Figure 8, UPSO yielded a slightly lower average minimum entropy generation rate for all materials but copper. Nonetheless, HS was able to achieve a better answer in all cases, so we consider that the difference in the data is mainly due to HS's high dispersion. Moreover, we observed that the number of required iterations remains quite steady for all materials, and even though HS did almost six times more iterations than UPSO, it was about 20 times faster.

\subsubsection{Tests for different dissipated power}

We fixed the material to copper (sinceitallowed for the minimum entropy) and varied the heat generation, ranging from $150 \mathrm{~W}$ and up to $1000 \mathrm{~W}$, with $50 \mathrm{~W}$ steps. In order to facilitate data comparison, we use the same organization style as in Khan, Kadri and Ali (2013), Adham, Mohd-Ghazali and Ahmad (2014). Thus, Table 10 shows the optimal designs achieved with HS and UPSO in terms of three design variables (i.e., $K n, \alpha_{c}$ and $\beta$ ) and three performance parameters (i.e., $R_{t h}, \Delta P$ and $\dot{s}_{g e n}$ ).

For all designs, we found that the channel height and the volume flow rate remains close to the upper limits (50 $\mathrm{mm}$ and $0.01 \mathrm{~m}^{3} / \mathrm{s}$, respectively), as expected. In the same way, higher heat flow rates lead to higher entropy generation rates. The thermal resistance diminishes as the generated heat rises, since a fixed flow requires that the minimum resistance decreases in order to satisfy the increased power dissipation from the chip. The pressure drop estimated by HS was consistently higher than the reported by UPSO although there is some kind of oscillation in their values. Additionally, we observed that the optimal channel aspect ratio $\left(\alpha_{c}\right)$ decreases when the heat transfer rate increases, with an approximate rate of $4 \times 10^{-6} 1 / \mathrm{W}$, making channels highly rectangular.

It was also observed that the pressure drop increases at a rate of $1.15 \mathrm{~Pa} / \mathrm{W}$ and that a high fraction of $\dot{S}_{g e n, \min }$ is due to heat transfer (Figure 9), while the contribution of mass transfer $\left(\dot{S}_{\text {gen,ff }}\right)$ is reduced. As it was anticipated, these results show a system highly dependent of the heat transfer mechanism. Moreover, we appreciated a rise in the heat sink base temperature $\left(T_{b}\right)$ with the increased heat flow (Figure 10). For a traditional electronic device, $T_{b}>345 \mathrm{~K}$ may compromise its performance, so special care must be taken into account. On this regard, we show that for heat transfer rates over $500 \mathrm{~W}$ (piecewise box), the device will misbehave, so additional variables, such as the properties of the fluid, must be included in the model.

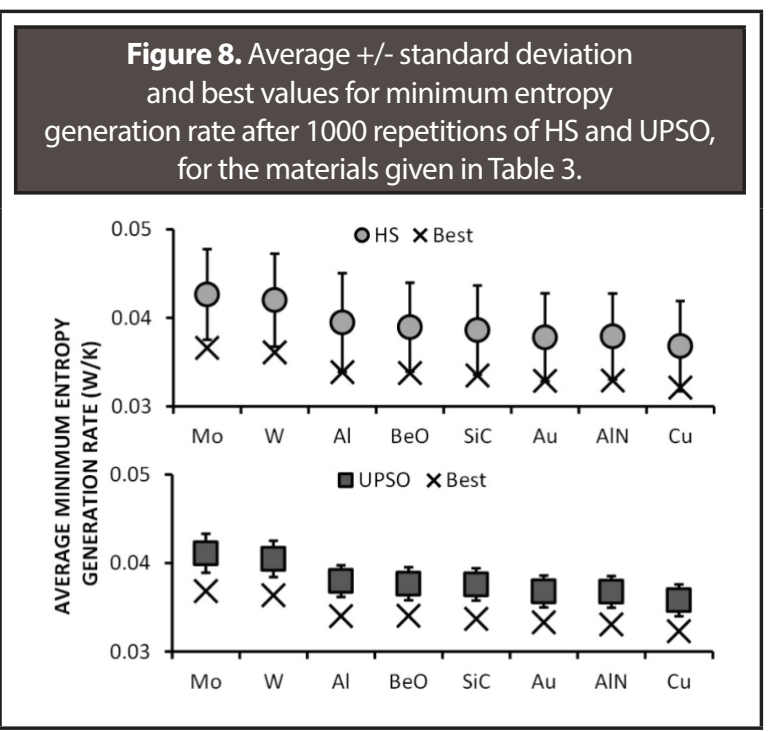




\begin{tabular}{|c|c|c|c|c|c|c|c|c|c|c|c|c|}
\hline \multirow[t]{2}{*}{$\dot{Q}(W)$} & \multicolumn{2}{|c|}{$K n$} & \multicolumn{2}{|c|}{$a_{c}=2 w_{c} / H_{c}$} & \multicolumn{2}{|c|}{$\beta=w_{c} / w_{w}$} & \multicolumn{2}{|c|}{$R_{t h}(W / K)$} & \multicolumn{2}{|c|}{$\Delta P(P a)$} & \multicolumn{2}{|c|}{$\dot{S}_{g e n}(\mathrm{~W} / \mathrm{K})$} \\
\hline & HS & UPSO & HS & UPSO & HS & UPSO & $\mathrm{HS}$ & UPSO & HS & UPSO & HS & UPSO \\
\hline 150 & 0.049 & 0.019 & 0.0056 & 0.0068 & 2.12 & 3.33 & 0.1184 & 0.1226 & 125 & 109 & 0.032 & 0.032 \\
\hline 200 & 0.022 & 0.063 & 0.0054 & 0.0045 & 2.55 & 2.13 & 0.1138 & 0.1132 & 165 & 181 & 0.052 & 0.053 \\
\hline 250 & 0.035 & 0.051 & 0.0044 & 0.0047 & 2.32 & 1.53 & 0.1089 & 0.1118 & 241 & 204 & 0.077 & 0.078 \\
\hline 300 & 0.016 & 0.089 & 0.0045 & 0.0036 & 2.70 & 1.84 & 0.1078 & 0.1096 & 272 & 237 & 0.106 & 0.107 \\
\hline 350 & 0.022 & 0.010 & 0.0043 & 0.0043 & 2.63 & 1.72 & 0.1076 & 0.1053 & 271 & 395 & 0.139 & 0.141 \\
\hline 400 & 0.023 & 0.011 & 0.0039 & 0.0045 & 1.77 & 2.67 & 0.1052 & 0.1071 & 343 & 309 & 0.175 & 0.177 \\
\hline 450 & 0.018 & 0.034 & 0.0032 & 0.0036 & 2.25 & 2.22 & 0.1014 & 0.1039 & 513 & 400 & 0.215 & 0.215 \\
\hline 500 & 0.003 & 0.011 & 0.0040 & 0.0037 & 1.54 & 2.14 & 0.1024 & 0.1018 & 463 & 603 & 0.258 & 0.261 \\
\hline 550 & 0.018 & 0.015 & 0.0033 & 0.0048 & 1.54 & 1.51 & 0.1010 & 0.1046 & 540 & 442 & 0.304 & 0.309 \\
\hline 600 & 0.008 & 0.032 & 0.0040 & 0.0030 & 1.43 & 1.66 & 0.1026 & 0.1016 & 471 & 567 & 0.356 & 0.356 \\
\hline 650 & 0.027 & 0.013 & 0.0031 & 0.0032 & 1.59 & 1.58 & 0.0996 & 0.0999 & 713 & 657 & 0.408 & 0.407 \\
\hline 700 & 0.009 & 0.021 & 0.0033 & 0.0038 & 2.06 & 1.38 & 0.1008 & 0.1020 & 541 & 552 & 0.462 & 0.467 \\
\hline 750 & 0.044 & 0.009 & 0.0024 & 0.0036 & 1.78 & 1.90 & 0.0980 & 0.1005 & 930 & 630 & 0.522 & 0.522 \\
\hline 800 & 0.067 & 0.025 & 0.0017 & 0.0029 & 2.88 & 1.29 & 0.0973 & 0.0997 & 978 & 786 & 0.581 & 0.585 \\
\hline 850 & 0.028 & 0.079 & 0.0023 & 0.0019 & 2.65 & 2.44 & 0.0976 & 0.0990 & 916 & 784 & 0.644 & 0.646 \\
\hline 900 & 0.033 & 0.064 & 0.0023 & 0.0021 & 2.15 & 1.72 & 0.0973 & 0.0991 & 955 & 880 & 0.709 & 0.716 \\
\hline 950 & 0.050 & 0.082 & 0.0019 & 0.0024 & 2.16 & 1.51 & 0.0966 & 0.0992 & 1085 & 951 & 0.777 & 0.788 \\
\hline 1000 & 0.004 & 0.091 & 0.0027 & 0.0018 & 1.37 & 1.50 & 0.0974 & 0.0986 & 973 & 945 & 0.848 & 0.855 \\
\hline
\end{tabular}

Figure 9. Increase of the minimum total entropy generation rate and its components by heat transfer $(h t)$ and fluid friction (ff), as a function of the total heat transfer rate, using HS.

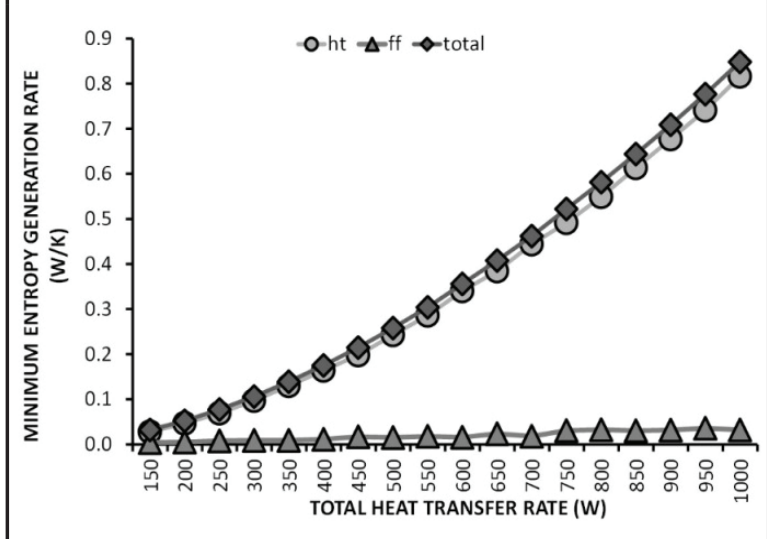

Those simulation results could guide us in defining safe operational conditions.

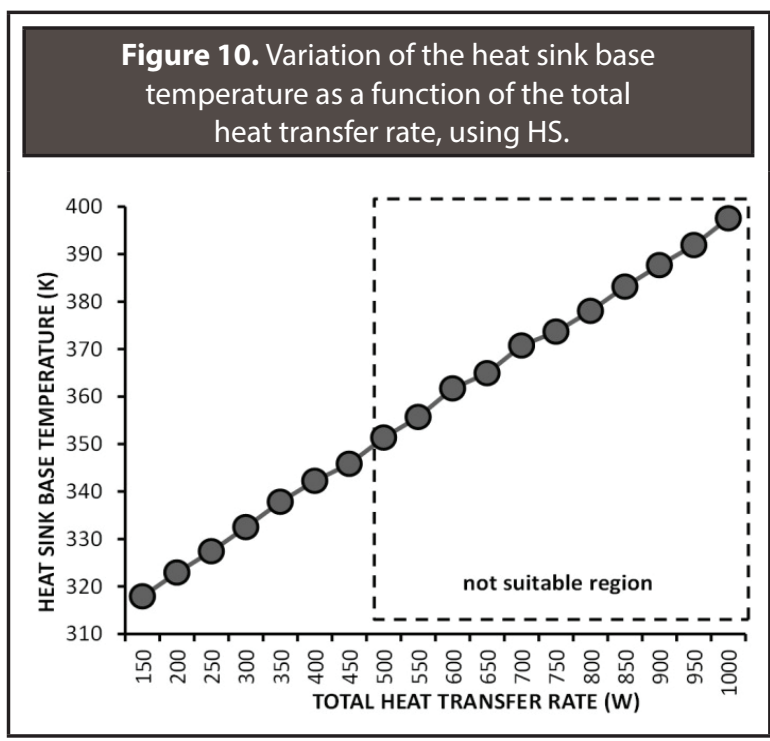




\begin{tabular}{|c|c|c|c|c|c|c|c|c|c|c|c|c|c|c|c|c|}
\hline \multirow{2}{*}{$K n$} & \multirow{2}{*}{$\begin{array}{c}G \\
\left(m^{3} / s\right)\end{array}$} & \multicolumn{3}{|c|}{$a_{c}=2 w / H_{c}$} & \multicolumn{3}{|c|}{$\beta=w_{c} / w_{w}$} & \multicolumn{3}{|c|}{$R_{t h}(W / K)$} & \multicolumn{3}{|c|}{$\Delta P(P a)$} & \multicolumn{3}{|c|}{$\dot{S}_{g e n, \min }(W / K)$} \\
\hline & & $G A$ & $H S$ & UPSO & $G A$ & $H S$ & UPSO & $G A$ & $H S$ & UPSO & $G A$ & $H S$ & UPSO & $G A$ & $H S$ & UPSO \\
\hline \multirow{3}{*}{0.1} & 0.005 & 0.081 & 0.018 & 0.018 & 2.69 & 1.40 & 1.38 & 0.186 & 0.215 & 0.215 & 859 & 1348 & 1366 & 0.267 & 0.307 & \begin{tabular}{|l|}
0.307 \\
\end{tabular} \\
\hline & 0.007 & 0.097 & 0.021 & 0.021 & 3.91 & 1.65 & 1.63 & 0.141 & 0.176 & 0.175 & 841 & 1370 & 1404 & 0.222 & 0.274 & 0.274 \\
\hline & 0.009 & 0.119 & 0.024 & 0.024 & 4.75 & 1.88 & 1.95 & 0.122 & 0.158 & 0.160 & 819 & 1390 & 1301 & 0.202 & 0.263 & 0.263 \\
\hline \multirow{3}{*}{0.01} & 0.005 & 0.086 & 0.024 & 0.025 & 3.05 & 1.95 & 1.96 & 0.195 & 0.212 & 0.212 & 1530 & 1308 & 1304 & 0.288 & 0.303 & 0.303 \\
\hline & 0.007 & 0.104 & 0.029 & 0.028 & 5.20 & 2.30 & 2.25 & 0.153 & 0.172 & 0.171 & 1451 & 1320 & 1380 & 0.250 & 0.269 & 0.269 \\
\hline & 0.009 & 0.130 & 0.033 & 0.032 & 6.20 & 2.62 & 2.52 & 0.138 & 0.154 & 0.152 & 1439 & 1324 & 1400 & 0.241 & 0.256 & 0.257 \\
\hline \multirow{3}{*}{0.001} & 0.005 & 0.091 & 0.026 & 0.026 & 3.11 & 2.05 & 1.99 & 0.198 & 0.212 & 0.212 & 1603 & 1326 & 1356 & 0.293 & 0.303 & 0.304 \\
\hline & 0.007 & 0.112 & 0.030 & 0.030 & 5.27 & 2.40 & 2.36 & 0.158 & 0.172 & 0.172 & 1500 & 1346 & 1350 & 0.257 & 0.269 & 0.269 \\
\hline & 0.009 & 0.136 & 0.034 & 0.034 & 7.04 & 2.74 & 2.67 & 0.143 & 0.153 & 0.153 & 1457 & 1344 & 1372 & 0.248 & 0.257 & 0.257 \\
\hline
\end{tabular}

\subsubsection{Data Comparison}

Finally, we compare our simulated designs (using HS and UPSO) against those reported by Khan, Kadri and Ali (2013) using Genetic Algorithm (GA). In the same way as Khan et al. did, we varied $K n$ and $G$, and assumed the same design variables $\left(H_{c}, w_{c}\right.$, and $w_{w}$ ). Results are shown in Table 11. For a given value of $K n$ and $G$, we obtained quite different aspect ratios $\left(\alpha_{c}\right.$ and $\left.\beta\right)$, even though they share the same trend. Unfortunately, analysing their data it is easy to observe that their results are above the upper limit imposed for their simulations (Table 2 in Khan, Kadri and Ali (2013)). This hinders a more detailed comparison.

\section{CONCLUSIONS AND}

\section{RECOMMENDATIONS}

It was accomplished a systematic and thorough analysis, related to the effectiveness of the optimization algorithms HS and UPSO for the design of optimal microchannels. It was also evident that the Monte Carlo strategy, a well-known powerful technique, can be used as a first approach in design engineering, especially to grasp an idea of the order of magnitude and of the relative importance of the parameters. During this study we explored two modern algorithms for optimising the design of a microchannel heat sink. We found that both approaches yielded precise results, even though they have some particularities. In the case of Harmony Search (HS), we found that it always provided the best answer (i.e. the one with the minimum entropy generation rate), but its data dispersion was higher (about two times), thus allowing Unified Particle Swarm Optimisation (UPSO) to generate results with a lower average minimum entropy generation rate. We also noted that HS presented a greater chance (24\%) of finding a better solution than PSO (10\%). Moreover, we determined that HS requires several times more iterations than UPSO (about five for this particular research) but since each iteration has quite a straightforward logic, the convergence time of HS ends up being way shorter than UPSO's (about 19 times according to our data). We also determined that both algorithms seem to be stable when varying the material of the heat sink and the heat generation rate, providing practical values for the designs. Of all the materials tested, it was determined that copper generates the minimum entropy. However, a proper selection of the material must not only consider thermal conductivity, but also variables such as manufacturing costs, operating conditions, and other factors relevant to the design specifications, even its own weight. Nonetheless, HS and UPSO behaved quite well for this application, so we 
recommend using them and invite the reader to test them with a multi-objective model that incorporates the aforementioned variables in order to achieve a more realistic and buildable design. Finally, we think these findings can be used by microchannels design engineers to significantly shorten the time consuming optimal design process.

\section{ACKNOWLEDGEMENTS}

The authors would like to express their gratitude to Vicerrectoría de Investigación y Extensión, at Universidad Industrial de Santander (Colombia), for the support granted through project 1807.

\section{REFERENCES}

Abdel-Raouf, 0. y Abdel-Baset-Metwally, M. (2013). A Survey of Harmony Search Algorithm. International Journal of Computer Applications, 70(28), pp.17-26.

Adham, A.M.; Mohd-Ghazali, N. y Ahmad, R., (2014). Optimization of a Rectangular Microchannel Heat Sink Using Entropy Generation Minimization (EGM) and Genetic Algorithm (GA). Arabian Journal for Science and Engineering, 39(10), October, pp. 72117222.

Adham, A.M.; Mohd-Ghazali, N. y Ahmad, R., (2012). Optimization of an Ammonia-Cooled Rectangular Microchannel Heat Sink Using Multi-Objective NonDominated Sorting Genetic Algorithm (NSGA2). Heat and Mass Transfer, 48(10), October, pp.17231733.

Amaya, I.; Cruz, J. y Correa, R. (2015). Harmony Search Algorithm: a Variant with Self-Regulated Fretwidth. [En línea] Applied Mathematics and Computation, 266, September, pp. 1127-1152. Disponible en: http://linkinghub.elsevier.com/retrieve/pii/ S0096300315008218.

Bejan, A. (1996). Entropy Generation Minimization: The New Thermodynamics of Finite-Size Devices and Finite-Time Processes. [En línea] AIP Journal o Applied Physics. New York: CRC press. Disponible en: http://scitation.aip.org/content/aip/journal/ jap/79/3/10.1063/1.362674

Chen, C.T. y Chen, H.I. (2013). Multi-Objective Optimization Design of Plate-Fin Heat Sinks Using a DirectionBased Genetic Algorithm. Journal of the Taiwan
Institute of Chemical Engineers, 44(2), March, pp.257-265.

Cruz, J.; Amaya, I. y Correa, R. (2015). Optimal Rectangular Microchannel Design, Using Simulated Annealing, Unified Particle Swarm and Spiral Algorithms in the Presence of Spreading Resistance. Applied Thermal Engineering, 84, June, pp. 126-137.

Derrac, J. et al. (2011). A Practical Tutorial on the Use of Nonparametric Statistical Tests as a Methodology for Comparing Evolutionary and Swarm Intelligence Algorithms. Swarm and Evolutionary Computation, 1(1), March, pp. 3-18.

Hajialigol, N. et al., (2015). MHD Mixed Convection and Entropy Generation in a 3-D Microchannel Using Al203-Water Nanofluid. Journal of the Taiwan Institute of Chemical Engineers, 46, January, pp. 3042.

Hamadneh, N. et al. (2013). Design Optimization of Pin Fin Geometry Using Particle Swarm Optimization Algorithm. PloS one, 8(5), May, p. 9.

Hatami, M. y Ganji, D.D. (2014). Thermal and Flow Analysis of Microchannel Heat Sink (MCHS) Cooled by $\mathrm{Cu}-$ Water Nanofluid Using Porous Media Approach and Least Square Method. Energy Conversion and Management, 78, February, pp.347-358.

Karathanassis, I.K. et al. (2013). Multi-Objective Design Optimization of a Micro Heat Sink for Concentrating Photovoltaic/Thermal (CPVT) Systems Using a Genetic Algorithm. Applied Thermal Engineering, 59(1-2), September, pp. 733-744.

Karunanithi, A.K. y Hassanipour, F. (2014). Multilayer minichannel heat sinks: The effect of porosity scaling on pressure drop. En: 5th International Conference on Porous Media and Their Applications in Science, Engineering and Industry. Kona, Hawaii, EE.UU. ECI Symposium Series.

Khan, W.A.; Kadri, M.B. y Ali, Q. (2013). Optimization of Microchannel Heat Sinks Using Genetic Algorithm. Heat Transfer Engineering, 34(4), January, pp. 279287.

Leng, C. et al. (2015). Multi-Parameter Optimization of Flow and Heat Transfer for a Novel Double-Layered Microchannel Heat Sink. International Journal of Heat and Mass Transfer, 84, May, pp. 359-369.

Mohammed-Adham, A.; Mohd-Ghazali, N. y Ahmad, R. (2013). Thermal and Hydrodynamic Analysis of 
Microchannel Heat Sinks: A Review. Renewable and Sustainable Energy Reviews, 21, pp. 614-622.

Rao, R.V. y Waghmare, G.G. (2014). Multi-Objective Design Optimization of a Plate-Fin Heat Sink Using a Teaching-Learning-Based Optimization Algorithm. Applied Thermal Engineering, 76, February, pp. 521529.

Rimbault, B.; Nguyen, C.T. y Galanis, N. (2014). Experimental Investigation of CuO-Water Nanofluid Flow and Heat Transfer Inside a Microchannel Heat Sink. International Journal of Thermal Sciences, 84, October, pp. 275-292.

Satpati, B.; Koley, C.y Datta, S. (2014). Robust PID Controller Design Using Particle Swarm Optimization-Enabled Automated Quantitative Feedback Theory Approach for a First-Order Lag System with Minimal Dead Time. Systems Science \& Control Engineering, 2(1), pp. 502-511. 